
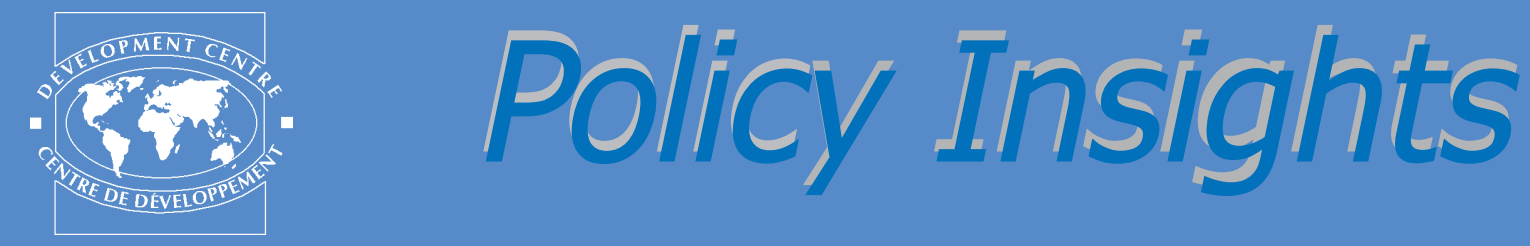

.

May 2006

\title{
Is More Money Enough to Fix Africa's Transport Infrastructure?
}

by Andrea Goldstein and Céline Kauffmann

Policy Insights No. 21 is derived from the African Economic Outlook 2005/2006, a joint publication of the African Development Bank and the OECD Development Centre www.oecd.org/dev/publications/africanoutlook

- Transport infrastructure has been dangerously neglected in recent times

- Lack of transport infrastructure impedes economic integration and poverty reduction

- Involving the private sector in financing the transport infrastructure is proving harder than anticipated

\section{In a continent of stranded mobility...}

The weakness of today's Africa transport infrastructure is striking compared to other developing regions. SubSaharan Africa accounts for only 3 per cent of the rail transport of developing countries, but has 17 per cent of the population and 7 per cent of the GDP. Under a fifth of its road network is paved, compared to over a quarter in Latin America and over two fifth in South Asia. Even paved roads are severely affected by systematic axle overloading of trucks and poor drainage, with dramatic consequences on safety. In 1999, about 10 per cent of global road deaths occurred in sub-Saharan Africa with only some 4 per cent of the world's registered vehicles.

Despite the importance of airports and seaports for longdistance freight, only a few airports (in Egypt, Cape Verde, Ethiopia, Morocco, Ghana and South Africa) have attained FAA Category I status, required for international flights. Only 4.5 per cent of global air traffic is in Africa, yet its share of accidents reached 25 per cent in 2004. Only one African seaport is owned by one of the five largest global port operators known worldwide for their efficiency and most container terminals are reaching or have reached capacity limits, and are under-equipped. Even Durban has had a congestion surcharge imposed by shipping lines for two years.
The African Economic Outlook notes that geography, demography and lack of resources are all major impediments to transport development in Africa. Fifteen of the continent's 53 countries are landlocked and population densities in the interior are very low, making infrastructure investments and maintenance very expensive.

\section{..substantial money input is required}

The World Bank estimates that African countries will need to spend the equivalent of 4 per cent of GDP every year for the coming decade, just on roads.

Yet, throughout the 1990s, infrastructure was largely overlooked in the allocation of official development assistance in favour of the social sectors. It is only recently, with the September 2005 UN Millennium plus 5 Summit and the report of the Commission for Africa, that infrastructure again became a top priority on the international development agenda. Meanwhile, increasing involvement in the sector of non-DAC donors, notably China and Arab countries, has been observed. 


\section{Chinese Assistance to Angola and Mozambique}

Since early 2005, Angola has seen a dramatic expansion of its relations with China. China Eximbank has extended $\$ 2$ billion worth of loans to rehabilitate roads and railways, especially in mineral-rich Benguela. Non-Chinese suppliers are excluded from the bidding, thus hampering the development of the local work force. Chinese contractors are also involved in over one-third of Mozambique's current road construction programme as a result of tied aid. According to the Mozambican authorities Chinese construction companies deliver overall good quality outputs, within schedule and 25 per cent to 50 per cent cheaper than the competitor's offers.

Short of money and burdened with inefficient state-owned monopolies, African countries are seeking private-sector participation. Various forms of public-private partnerships have been tried in airports, seaports and railways, more rarely for roads. Investors' perception of high risk renders full privatisation impractical, so most private participation in transport infrastructure has taken the form of leases or concessions.

The results have been mixed says the African Economic Outlook. The private sector is increasingly important in the management of airfield, gates, jet-ways, and facilities associated with the movement of aircraft, and in "landside" services. Cargo-handling costs have fallen where competition among service providers has been introduced (charges are between $\$ 60-\$ 75$ per $20 \mathrm{ft}$ container in Dakar, Abidjan and Douala compared to $\$ 200$ in Lagos). This "operating" part is potentially the most profitable and as such it can be "unbundled" and easily divested.

Fixed infrastructure traditionally requires large-scale investment that private investors more than often fail to deliver. Wars and natural disasters have led to the cancellation of several railway concessions. Even in less dramatic cases, the upgrading and extension of networks have continued to be largely funded by multilateral and bilateral loans on concessional terms.

\section{Money alone is not enough}

A point often missed is that transport infrastructure is crucial for poverty reduction. To derive the maximum benefits from private sector participation, efficient regulation is needed. This should avoid excessive prices and inadequate service, while ensuring optimal access, maintenance, and investment. The key factors of success include strong government commitment to ensure the credibility of the reform process; proper sequencing; and the creation of an independent and well-enforced regulatory body prior to divestiture.

The role of the state is also crucial for improving infrastructure planning and coherence with national propoor growth strategies and medium-term expenditure frameworks. Up-front planning should maximise the benefits from infrastructure projects while minimising their environmental and social costs. Attention needs to be paid to the complementarities of different means of transport; the importance of transport hubs and markets; and the development of secondary roads.

States are not alone in that task. Community participation at all stages has proved helpful in identifying priorities, creating employment and ensuring long-term maintenance. Involving women - who account for two-thirds of the rural transport effort - is also key to aligning transport development with poverty reduction goals. Finally, careful co-ordination with regional and continental authorities (such as the NEPAD) rationalises state action on crossborder projects, while offering the country benefits from larger markets.

\section{www.oecd.org/dev/insights \\ www.oecd.org/dev/briefs \\ www.oecd.org/dev/wp \\ OECD $\ll$}

\footnotetext{
Readers are encouraged to quote or reproduce material from OECD Development Centre Policy Insights for their own publications. In return, the Development Centre requests due acknowledgement and a copy of the publication. Full text of Policy Insights and more information on the Centre and its work are available on its web site:

www.oecd.org/dev
}

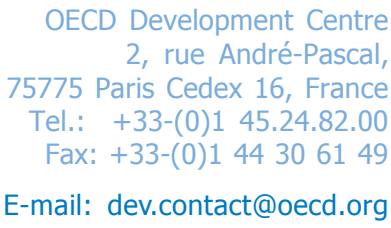

